XXVII.-Account of Experimental Observations on the Development and Gronth of Salmon-Fry, from the exclusion of the Ova to the age of two years. By Mr Johv Seaw, Drumlanrig. Communicated by James Wilson, Esq. F.R.S.E.

(Read 16th December 1839.)

" Experience once recognised as the fountain of all our knowledge of nature, it follows that in the study of nature and its laws, we ought at once to make up our minds to dismiss as idle prejudices, or at least suspend as premature, any preconceived notions of what might or ought to be the order of nature in any proposed case, and content ourselves with observing, as a plain matter of fact, what is." - Sir John Herschel's Discourse on the Study of Natural Philosophy.

That the facts which I communicate regarding the natural history of the salmon in its earlier stages, may not appear altogether undeserving of consideration, I may premise that my remarks have not proceeded from hasty or imperfect observation, but from the experience of many years sedulously devoted to the subject, the whole of my life, with the exception of a few seasons, having been spent on the banks of streams where salmon are in the habit of depositing their spawn, and where of course the parr is likewise abundant. My opportunities of observation have thus been as ample, as my efforts have been unremitting and laborious, to discover the true history of this invaluable species. I shall here present a brief abstract of my earlier proceedings in relation to the subject.*

I had long been of opinion, in opposition to the sentiments entertained by the majority of authors, that the fish commonly called parr, was the natural produce of the salmon, and that all recorded attempts to trace the history of the latter fish were fanciful in their nature, and delusive in their results. To enable me to watch the progressive growth of parr, I caught seven of these small fishes on the 11th of July 1833, and placed them in a pond supplied by a stream of

" My first paper, entitled " An Account of some Experiments and Observations on the Parr, and on the Ova of the Salmon, proving the Parr to be the young of the Salmon," was published in the Edinburgh New Philosophical Journal for July 1836, vol. xxi. p. 99. My second paper, under the title of " Experiments on the Development and Growth of the Fry of the Salmon, from the exclusion of the Ovum to the age of six months," was read before the Royal Society of Edinburgh on the 18th December 1837, and was published in the Edinburgh New Philosophical Journal for January 1838, vol. xxiv. p. 165. My third and concluding communication, which the Society now honours by its reception, contains an account of the continuance and confirmation of these experiments, with an introductory reference to the papers above named. 
wholesome water. There they continued to thrive remarkably well, and were seen catching flies and other insects, and sporting on the surface in perfect health. In the month of April following (1834), they began to assume a different aspect from that which they exhibited when first put into the pond, and this change was evident enough even while they continued swimming at large in the water; but wishing to examine them more particularly, and at the same time to convince others of the fact of their having changed their external character, I caught them with a casting-net, on the 17th May 1834, and satisfied every individual present that they had assumed the usual appearance of what are called salmon smolts or fry. They were now of a fine deep blue upon the back, with a delicate silvery appearance on the sides, and the abdomen white; these silvery scales came easily off upon the hand. A circumstance occurred about the first week of May, which it may be proper to mention, as illustrating in some manner what may be deemed the migratory instinct of these fishes. They seemed to me at this time to be decreasing in numbers, and I found, on examination, that some had leapt altogether out of the pond, and were lying dead at a short distance from its edge.

In March 1835, I again took twelve parrs from the river of a larger size, that is, about six inches long ; they then bore the perpendicular bars, and other usual characters of that fish. These I also transferred to a pond prepared for the purpose, and, by the end of April, they too assumed the characters of the salmon-fry, -the bars becoming overlayed by the new silvery scales, which parrs of two years old invariably assume before departing towards the sea. From these experiments I had no doubt that the larger parrs observable in rivers in autumn, winter, and early spring, were in reality the actual salmon-fry advancing to the conclusion of their second year, and that the smaller summer parrs (called in Dumfriesshire May parrs), were the same species, but younger as individuals, and only entering upon their second year. This, then, I conceived to be the detection of the main error of preceding observers, who had uniformly alleged that salmon-fry attain a size of six or eight inches in as many weeks, and after the lapse of this brief period take their departure to the sea. It is the rapidity with which the two year old parr assumes the aspect of the salmon-fry that has led to this false conclusion, and superficial or hasty observers, taking cognizance, 1st, of the hatching of the ova in early spring, and, $2 d l y$, of the sea-ward migration of smolts soon afterwards, have imagined these two facts to take place in immediate or speedy succession. I may now mention what actually becomes of these young fishes for some weeks after they are hatched.

That the fish in question should not be found in the river in an earlier state than that in which it is named the May or summer parr, had long appeared to me to be an extraordinary and perplexing circumstance. I therefore made a minute examination of the streams where the old salmon had spawned the preceding winter, and $I$ there found in vast numbers a very small but active fish, which 
I concluded to be the young parr, or samlet of the season. To prove the fact, I scooped up with a gauze-net two or three dozen of them, on the 15th of May 1834. They measured about an inch in length ; their heads were large in proportion to their bodies, and the latter tapered off toward the tail, in the form of a wedge. The small ransverse bars, characteristic of the parr, were already distinctly marked. I placed them in two ponds, each provided with a run of water, where they throve well. In the course of the succeeding May (1835), that is, when they were more than a year old, and had been twelve months in my possession, I took a few of them from the pond for the purpose of examination. They had increased to the length of $3 \frac{1}{2}$ inches, on an average, and it is important to remark, that they corresponded in every respect with the parr of the same age which occurred in the river; but neither as yet indicated any approach to the silvery aspect of the smolt. Being satisfied, however, from the result of my former experiments on the parr, that they would ultimately assume that silvery aspect, I continued to detain them in the pond, and, accordingly, in May 1836, they were transmuted into smolts or salmon-fry, commonly so called. At this time they measured $6 \frac{1}{2}$ inches in length, their colour on the back a beautiful deep blue, the sides bright and silvery, the dorsal, caudal, and especially the pectoral fins, tipt with black, the abdomen, ventral, and anal fins, white. The undoubted smolts of the river were at this time descending sea-wards, and the most careful comparison of these with those in my possession did not elicit the slightest difference between the two. Mine had completed their second year, and is it likely that those in the river which so identically resembled them, were only a few weeks old?

The minute but active fish above alluded to, is at that early period to be no where found except in those streams (or their immediate vicinity) in which the old salmon had deposited their spawn during the preceding winter. Early in April 1835, I discovered them in one of these streams, but so young and weak, owing to their very recent emergence from the spawning-bed, as to be unable to struggle with the current where it flowed with any strength or rapidity. They therefore betook themselves to the gentler eddies, and frequently into the small hollows produced in the shingle by the hoofs of horses which had passed the ford. In these comparatively quiet places, and covered by a slight current of a few inches in depth, they continued with their little tails in constant motion, till such time as my near approach was perceived, when they immediately darted beneath the stones. They remain with these habits, and in the situations just mentioned, during the months of April, May, and even June; but as they increase in size and strength, they scatter themselves all over the shallower parts of the river, especially wherever the bottom is composed of fine gravel. They continue, in truth, comparatively unobserved throughout the whole of the first summer, being seldom taken by the angler during that season. But when the two-year-olds have disappeared (as smolts) in spring, these smaller fishes, now entering their second 
year, become bolder and more apparent, and now constitute the May and summer parr of anglers. But their timid habits during the first few months of their existence, and their consequent concealment in the shingle, greatly screen them from observation during that period, and have led to the erroneous belief, that the silvery smolts were the actual produce of the season, and were only few weeks old. It certainly seems singular that it should never have occurred to any intelligent angler to inquire what had become of the older generation of parr, that is of the comparatively large individuals which he might have captured late in autumn and in earliest spring, but none of which he can detect after the departure of the so-called smolts. If the two are not identical, how does it happen that the one so constantly disappears simultaneously with the other? Yet no one alleges that he has ever seen parr, as such, performing their migration towards the sea. They cannot do so, because they have been previously converted into smolts. I shall here allude briefly to three different occasions on which I have had an opportunity of witnessing the first migration of smolts or converted parr, that is, their descent in small shoals towards the sea. The first of these was in the first week of May 1831. I was able deliberately to inspect them as the several shoals arrived behind the sluices of a salmon cruive, and while they yet remained in the water, and were swimming in a particular direction, indistinct transverse lateral bars might still be seen, but as they changed their position, these became as it were lost in the silvery lustre. I also examined many of them in the hand, and could there also, by holding them at a certain angle in relation to the eye, produce the barred appearance, but when the fish were held with their broad side directly opposed to view, the character alluded to could not be seen. Its actual existence, however, could be easily proved by removing the deciduous silvery scales, when the barred markings became apparent, and, of course, continued so to whatever light exposed. My next opportunity occurred on the 3d of May 1833. The appearance was exactly the same as that which I have just described. They passed down the river in small family groups or shoals of from forty to sixty and upwards, their rate of progression being about two miles an hour. The caution which they exercised in descending the several rapids they met with in the course of their journey was very amusing.- They no sooner came within the influence of any rapid current than they in an instant turned their heads up the stream, and would again and again permit themselves to be carried to the very brink, and as often retreat upwards, till at length one or two, bolder than the others, permitted themselves to be carried over the current, when the entire flock, one by one, disappeared, and then, so soon as they had reached comparatively still water, they again turned their heads towards the sea, and resumed their journey. The third opportunity to which I shall here refer occurred in May 1836, at which time, as I have stated, I compared a few of the descending smolts with those which (having been two years in my possession as parr) had, in the confine- 
ment of the pond, assumed the corresponding silvery aspect of the salmon-fry. The river during this month being remarkably low, I was thus enabled to ascertain more accurately the time during which they continued to migrate, which I found to be nearly throughout the whole of the month, but more especially in the course of the second week, in which the shoals were both larger, and more frequent in their successive arrivals. Their external aspect was the same as that of the former shoals, and the average length, as usual, from six to seven inches.

Having thus traced the progress of the parr from an inch in length, through its several stages up to the period of migration, I shall now detail my various experiments on the ova of the salmon, undertaken with a view to prove the identity of these two fish. On the 10th of January 1836, I observed a female salmon of considerable size (about $16 \mathrm{lb}$.), and two males, of at least $25 \mathrm{lb}$., engaged in depositing their spawn. The spot which they had selected for that purpose was a little apart from some other salmon which were engaged in the same process, and rather nearer the side, although still in pretty deep water. The two males kept up an incessant conflict during the whole of the day, for possession of the female, and, in the course of their struggles, frequently drove each other almost ashore, and were repeatedly on the surface displaying their dorsal fins, and lashing the water with their tails. Being satisfied that these were real salmon, there being at least ten brace of that fish engaged in the same process on the stream at the time, I took the opportunity of securing as much of the ova as I could possibly obtain. This I did three days after it was deposited, the males and female still occasionally frequenting the bed. The method by which I obtained the eggs was by using a thin canvass bag, stitched on a slight frame formed of small rod iron, in fashion of a large square landing-net, one person holding this bag a few inches farther down the stream than where the ova were deposited, and another with a spade digging up the gravel, the current carrying the eggs into the bag, while the greater portion of the gravel was left behind. Having thus obtained a sufficient quantity of the ova for my purpose, I placed them in gravel under a stream of water where I could have a convenient opportunity of watching their progress. The stream was pure spring water. On the 26th February, that is, forty-eight days after being deposited, I found on close inspection that they had some appearance of animation, from a very minute streak of blood which appeared to traverse for a short distance the interior of the egg, originating near two small dark spots not larger at that time than the point of a pin. These two dark spots, however, ultimately turned out to be the eyes of the embryo fish, which was distinctly seen resting against the interior surface of the egg a few days previous to its exclusion. On the 8th of April, which makes ninety days imbedded in the gravel, I found on examination that they were excluded from the egg, which was not the case a day or two previous. The temperature of the water at the time was $43^{\circ}$, the temperature of the water in the river $45^{\circ}$, and the temperature of the VOL. XIV. PART II. 
atmosphere $39^{\circ}$. On its first exclusion, the little fish has a very singular appearance. The head is large in proportion to the body, which is exceedingly small, and measures about five-eighths of an inch in length, of a pale blue or peach-blossom colour. But the most singular part of the fish is the conical bag-like appendage which adheres by its base to the abdomen. This bag is about twoeighths of an inch in length, of a beautiful transparent red, very much resembling a light red currant, and in consequence of its colour, may be seen at the bottom of the water when the fish itself can with difficulty be perceived. The body also presents another singular appearance, namely, a fin or fringe, resembling that of the tail of the tadpole, which runs from the dorsal and anal fins to the termination of the tail, and is slightly indented. This little fish does not leave the gravel immediately after its exclusion from the egg, but remains for several weeks beneath it with the bag attached, and containing a supply of nourishment, on the same principle, no doubt, as the umbilical vessel is known to nourish other embryo animals. By the end of fifty days, of the 30th May, the bag contracted and disappeared. The fin or tadpole-like fringe also disappeared by dividing itself into the dorsal, adipose, and anal fins, all of which then became perfectly developed. The little transverse bars, which for a period of two years (as I have already shewn) characterize it as the parr, also made their appearance. Thus, from the 10th January till the end of May, a period of upwards of 140 days was required to perfect this little fish, which even then measured little more than one inch in length, and corresponded in all respects with those on which I had formerly experimented, as well as with such as existed at that same time in great numbers in the natural streams.

Although I was myself satisfied by the preceding facts that parr and salmon fry were thus identical in kind, and differed only in respect to age, I was informed that my inferences were objected to, in as far as there was not sufficient evidence that the spawn experimented on was actually that of salmon, seeing that the same streams were accessible to other species of the genus. I therefore felt it incumbent on me to supply this desired link in the chain of evidence, and I accordingly repeated my experiments on ova which I saw excluded, which, in fact, I forced the salmon to exclude, in the manner after mentioned, preserving at the same time the skins of the parent fish, for the satisfaction of the curious or sceptical.

Before proceeding to make additional experiments, it was necessary to lay my experimental basins dry, not only for the purpose of removing the young salmon of the preceding season's produce, but also to enable me to fit them up on such a principle as would exclude any possibility of confusion either from the overflowing of the ponds themselves, or from the flooding of the river Nith, on the banks of which they are situate. The plan on which these ponds are constructed is shewn on Plate XXI. Every precaution was used not only to exclude 
error, but to place the young fry in circumstances as nearly resembling the state of nature as was consistent with their preservation.

The ponds, which are three in number, are two feet deep, and thickly embedded with gravel, while they are at the same time supplied with a small stream of spring-water in which the larvæ of insects abound. Pond No. 1 is 25 feet in length by 18 in breadth, and is fed by the stream, which debouches into it at the fall F. Pond No. 2 is 22 feet in length by 18 in breadth, and is fed from pond No. 1 at G, where the communication is carefully grated with wire. Pond No. 3 is 50 feet in length by 30 in breadth, and is fed by the stream at $F$, having no communication with either of the other ponds. The waste water from pond No. 1 is conducted into pond No. 2, through a square wooden pipe covered at the mouth with a wire-grating, the bars of which are about one-eighth of an inch apart. The waste water from pond No. 2 is conveyed under ground to the distance of 20 feet in a square wooden pipe grated in the same manner as the former. The waste water from pond No. 3 passes down a square wooden pipe 2 feet deep covered at the top with wire-gauze, and is conveyed under ground in a small covered drain to the distance of 20 feet from the pond. The water of the whole is then left to find its way to the river.

To prevent any communication arising from an accidental overflow of the ponds themselves, I raised embankments upon the intersecting walks of 2 feet in height, so that the several families of fish which the ponds contain can have no access, direct or indirect, to each other. Where the rivulet is divided for the purpose of supplying the several ponds, I have formed an artificial fall in each stream, of a construction to prevent the fish from ascending one stream and descending another. Finally, where the water discharges itself from the ponds, the channels are so secured by wire-grating that it is as impossible for the young fish to escape as for any other fish to have access to them. The whole occupies an area of nearly 80 feet square.

My experimental basins being thus prepared, my next object was to secure the fish, the progeny of which were to form the subject of experiment. With the view, therefore, of securing two salmon, male and female, while in the very act of continuing their kind, I provided myself with an iron hoop 5 feet in diameter, on which I fixed a net of a pretty large mesh, so constructed as to form a bag 9 feet in length by 5 in width. I then attached the hoop and net to the end of a pole 9 feet long, thus forming a landing-net on a large scale. The weight of the net with its iron hoop being upwards of $7 \mathrm{lb}$., it instantly sunk to the bottom on being thrown into the water.

Being thus prepared with all the means of carrying my experiment into practice, I proceeded to the river Nith on the 4th January 1837, and readily discovered a pair of adult salmon engaged in depositing their spawn. They were in a situation easily accessible, the water being of such a depth as to admit of my 
net being employed with certain success. Before proceeding to take the fish, I formed a small trench in the shingle by the edge of the stream, through which I directed a small stream of water from the river 2 inches deep. At the end of this trench, I placed an earthenware basin of considerable size, for the purpose of ultimately receiving the ova. I then, at one and the same instant, enclosed both the fish in the hoop, allowing them to find their way into the bag of the net by the aid of the stream. In capturing these fish, I considered myself fortunate in securing them by one cast of the net, for, in conducting the experiment of artificial impregnation, it appeared to me to be very desirable that the male should be taken, with the female of his own selection, at the very moment when they were mutually engaged in the continuance of their species. To take a female from one part of the stream and a male from another, might not have given the same chance of a successful issue to the experiment. Having drawn the fish ashore, I placed the female, while still alive, in the trench, and pressed from her body a quantity of ova. I then placed the male in the same situation, pressing from his body a quantity of milt, which, passing down the stream, thoroughly impregnated the ova. I then transferred the spawn to the basin, and deposited it in a stream connected with a pond previously formed for its reception, which, however, I have not considered it necessary to represent in the accompanying plan. The temperature of this stream was $39^{\circ}$, of the river from which the salmon were taken $33^{\circ}$, and of the atmosphere $36^{\circ}$. The skins of the parent salmon are now in my possession.

On examining the ova on the $23 \mathrm{~d}$ of February (fifty days after impregnation), I found the embryo fish distinctly visible to the naked eye, and even exhibiting some symptoms of vitality by moving feebly in the egg. The temperature of the stream was at this time $36^{\circ}$, and of the atmosphere $38^{\circ}$. On the 28th of April (114 days after impregnation), I found the young salmon excluded from the egg, which was not the case when I visited them on the previous day. The temperature of the stream was then $44^{\circ}$. The ova, which for some time previous to being hatched, had been almost daily in my hand for inspection, did not appear to suffer at all from being handled. When I had occasion to inspect the ovum, I placed it in the hollow of my hand, covered with a few drops of water, where it frequently remained a considerable time without suffering any apparent injury. The embryo, however, while in this situation, shewed an increased degree of activity by repeatedly turning itself in the egg, an action probably produced by the increase of temperature arising from the warmth of the hand.

On the 24th of May (twenty-seven days after being hatched), the young fish had consumed the yolk, but in a few days afterwards the whole of this family, with the exception of one individual, were found dead at the bottom of the pond, a circumstance which has occurred more than once in the course of my experiments, arising, I apprehend, from a deposition of mud, the same result having 
previously taken place, when the pond had not been sufficiently imbedded with gravel.

To shew the effects of increased temperature in hastening the development of the infant fish, I may relate an experiment which I made upon a few of the same ova, from which this family proceeded. On the 20th of April (106 days after impregnation), finding the ova alluded to unhatched, and the temperature of the stream being $41^{\circ}, I$ took four of them and placed them in a tumbler of water, covering the bottom with fine gravel, in which I imbedded the ova. I then suspended the tumbler from the top of my bed-room window, above which I placed a large earthenware jar, with a small spiggot inserted in its side, from which I easily directed a stream of pure spring water into the tumbler. The waste water was carried out at the window along a wooden channel fitted up for the purpose. As there was no fire in the bed-room, and the window facing the north, the temperature did not range very high, $47^{\circ}$ being the average, while the average temperature of the water in the tumbler was $45^{\circ}$. During the night, however, the temperature would be very considerably increased, and the consequence was, the young fish in the tumbler were hatched in thirty-six hours, while those remaining in the stream did not hatch till the 28th of April, a difference of nearly seven days. At this stage the little fish are so very transparent, that their vital organs are distinctly visible, and, when placed immediately under the eye of the observer, they present a very interesting appearance. The pectoral fin is continually in rapid motion, even when the fish itself is otherwise in a state of perfect repose. They also begin to manifest an increasing desire to escape observation, a principle wisely implanted for their better security, during so feeble and helpless a condition. On the 24th of May (thirty-nine days after their birth), the fish in the tumbler were completely divested of the yolk, and the characteristic bars of the parr had become visible. At this time they measured nearly one inch in length, and appeared to be in perfect health; but fearing that after the yolk was consumed, I should be unable to supply them with appropriate food, I returned them to the pond from which I had taken them on the 20th of April, where they perished with the rest of the family.

This last experiment proves, that by placing the ova under a temporary stream of water in the house, the development of the young may be materially accelerated, while it also shews that they may be kept alive for a considerable time afterwards; at all events, until the yolk, which I presume to be their sole support at this period, is totally consumed.

The next experiment, the circumstances of which I have to relate, has been attended with more success than those which I had previously made. The process of taking the adult fish, and all the circumstances attending the impregnac tion, were entirely similar in this case to that already narrated.

VOL. XIV. PART II. 
That the pedigree of the young fish may not be called in question, I have preserved the skins of the parents. The weight of the male when taken was $16 \mathrm{lb}$., and of the female $8 \mathrm{lb}$.

The spawn was impregnated and deposited in the stream immediately below the fall, pond No. 1. E, on the 27 th of January 1837 ; the temperature of the water in the stream being $40^{\circ}$, and that of the water in the river $36^{\circ}$. On the 21 st of March (fifty-four days after impregnation), the embryo fish were visible to the naked eye. On the 7th May (101 days after impregnation), they had burst the envelope, and were to be found amongst the shingle of the stream. The temperature of the water was at this time $43^{\circ}$, and of the atmosphere $45^{\circ}$. It is this brood which I have now had an opportunity of watching continuously for a length of time, that is, for more than the entire period which was required to elapse from their exclusion from the egg, until their assumption of those characters which distinguish the undoubted salmon-fry. I therefore desire, even at the risk of repetition, to describe their progressive growth during these important and usually misconceived stages of existence.* But before doing so, $I$ beg to be indulged in a few miscellaneous remarks.

It is indeed in no way surprising that any body of scientific men, before whom a portion of these observations on the growth of the salmon in fresh water may have been previously laid, should have been slow to express a decided opinion on the subject, more especially when the result of my experiments goes to prove facts so opposed to what has been the received opinion both of scientific and practical observers, ever since the natural history of the salmon became a subject of inquiry. I have no wish to attempt removing these opinions by the substitution of others which may be equally destitute of a correct foundation, but by the statement of facts resulting from the most careful and repeatedly verified experiments-experiments which, I believe, have been made by no other individual on the same principle for a similar purpose; for had they been so, I am persuaded the real history and economy of this valuable and interesting fish would long ere now have been more correctly understood by the community. However, should similar observations have been made, the results of which tend to support any material facts contradictory of those here stated, it would be most desirable that the scientific public should be immediately apprised of them.

It has been asserted, with some appearance of truth, in support of the old school theory, that owing to the comparatively limited range of my experimental ponds, the young salmon reared in them have not had a "supply of food sufficiently varied, or in sufficient quantity, to insure an equally rapid growth to those in the open river." This objection, I must repeat, is by no means tenable,

- I have transmitted a series of the specimens referred to, from the ovum to the smolt, and including the ordinary and transitionary state of the parr, to be exhibited when my paper is read. 
as the streams and ponds in which they have existed from their birth abound with every species of insect food peculiar to the river, and, at the same time, the fishes themselves (which are certainly the best test), are in the highest possible health and condition, and correspond in every respect with those in the river. I have already stated that the young of the salmon remain in the river for the first two years after their birth, being then known under the various local denominations of parrs, pinks, fingerlings, \&c. \&c. However, in order to prevent any misconception of the terms employed in the course of these details, I shall adhere to the name parr, as being the designation by which this fish is most generally known in Scotland.

The early or late hatching of the salmon-spawn in the river is no doubt in a great measure regulated by the temperature which may prevail after its deposition. In severe winters, when the temperature of the river for many weeks barely exceeds the freezing point, the ova remain in the gravel at the bottom of the stream during that period with the living principle comparatively suspended, until the more genial temperature of the spring brings that principle into more active operation. In the course of experiments made in the beginning of 1838 , I had an opportunity of observing the different effects of temperature in facilitating or retarding the development of the salmon-spawn. In ova placed in a stream of spring water, the average temperature of which was $40^{\circ}$, the embryo fish was visible to the naked eye by the end of the 60th day, and was hatched on the 108th day after impregnation. That which the same parent deposited the same day in the river, the average temperature of which during the eight following weeks did not exceed $33^{\circ}$, was not visible to the naked eye until the 90th day, and was not hatched until the 10th May, that is 131 days after impregnation. The temperature of the river, however, during the last forty days of that period, had considerably increased, and on the day on which the fishes were hatched, it had attained an elevation of $60^{\circ}$. Were it, then, the fact that the young salmon migrate to the sea the same season they are hatched, the effects of a mild or a rigid winter would alone regulate the period of their departure from the river. This, however, is not the fact, as the main body of the salmon-fry regularly quit our rivers about the first or second week in May, whatever may have been the temperature of the previous winter, and in this particular instance they were actually descending the river in shoals on the very day (10th May) on which that season's produce were only emerging from the ova.

Owing to the great family likeness which is known to exist amongst the young of the several species of the genus Salmo in their early stages, an idea has been entertained that unscientific observers are in the practice of confounding the progeny of the whole of the migratory species indiscriminately under the too general name of Parr. To obviate this inconvenience, and to mark the distinction 
of species in their earlier stages, recourse has been had to very fanciful and illdefined attributes; and I am of opinion that in almost every instance these vagne characters have been applied to individuals of the young of the real salmon, of which the characters had not been so fully developed as those of others, rather than to the young of any distinct species. With the view, therefore, of affording scientific men an opportunity of comparing the young of the salmon trout with that of the salmon, with which they are supposed to have been confounded, I have taken this opportunity of laying before the Royal Society a brood of the former produced by artificial impregnation, and exhibiting five successive stages, from the day on which they were hatched to the age of nine months, accompanied by the skins of the parent fishes. At the age of six months they bear no very marked resemblance to the young of the real salmon either in the parr or fry state, and as they advance in age and size, the resemblance becomes still slighter. However, on comparing them with the common trout, the resemblance is very striking, the general outline of the fish being much less elegant than that of the young salmon or parr, the external. markings being also more peculiarly those of the trout species, so that, in the absence of the parent skins, it would be a matter of difficulty to determine to which kind of trout they actually belong. A specimen of the young common trout of this season's produce, taken from the Clyde above the Falls, is also exhibited; so that the young of the three species most common to this locality (and of corresponding age), viz. Salmo salar, Salmo trutta, and Salmo fario, may be carefully compared. The ova of the Salmo eriox, which is less common in these tributaries, I have not as yet had an opportunity of experimenting upon.

To resume my history of the so-called parr. Having brought the series of experiments on the ovum of the salmon, begun in January 1837, to a satisfactory conclusion, it may be gratifying to those who have taken an interest in this curious inquiry, to be put in possession of the results. I have already detailed the particulars regarding the mode practised in capturing the parent salmon, the process of fecundating the ovum artificially with the milt from the male, and the appearance it presents from that period up to the exclusion of the young fish from the capsule of the ovum, which took place on the 7 th of May-101 days after impregnation. A complete series of specimens from the egg until the commencement of the third year, illustrates the following descriptive notes.

Specimens taken from the pond, when ten days old (16th May), had still a considerable portion of the vitelline bag attached to the abdomen. Specimens removed when forty-eight days old (24th June) had no recognisable bag, but the symmetry of the form was as yet but imperfectly developed. After the lapse of two months (7th July) the shape was found to be materially improved, and to exhibit in miniature much of the form and proportions of a mature fish. At the 
age of four months (7th September) the characteristic marks of the parr were clearly developed. Two months later (six months' old, 7th November) an accession both of size and strength was apparent, and on comparing the pond specimens with the parr of the river, no marked difference was perceptible. The average length at this time was three inches.

During the winter months, the general temperature of the rivers is so low, and the consequent deficiency of insect food so great, that the whole of the Scottish Salmonidæ which inhabit the fresh waters during that season, are well known to lose, rather than gain, in point of condition. The same rule holds in regard to the young salmon in the experimental ponds, although not to the same degree, they having maintained comparatively a superior condition throughout the winter to those found in the river of a corresponding age and size. The temperature of the ponds, averaging about $40^{\circ}$ during the winter, not only keeps the young fishes which occupy them in a more active condition, but the insects themselves are also more abroad, and thus afford a convenient supply of food not to be obtained by those at that time in the river, the average temperature of which, in ordinary winters, barely exceeds $34^{\circ}$. I shall now refer more specially to the specimens before the Society.

No. 6 is a specimen from pond No. 1, of the age of nine months, taken in the middle of February 1838. It exhibits little or no particular accession of size or condition to that of No. 5, but may serve to shew the general appearance of the several broods of the young salmon in my possession at the age of nine months.

No. 7 is a specimen twelve months old, taken from pond No. 1, on the 10th May 1838. It is much improved in condition, as well as in external appearance, in comparison to that taken in February, and has exchanged its dusky antumnal and winter's coating for that which may be called its summer dress.* It measures about $3 \frac{3}{4}$ inches in length, and is denominated, along with those of a corresponding age and size in the river, the "May Parr." Immediately after the migration of the two year-old parr (which the latter always affect about the beginning of May, under the name of salmon-fry), there is no other parr, besides such as have been recently hatched, to be found in the river, save those which correspond with this specimen, which is the Pink of the river Hodder, alluded to by Mr Yarrell. $\dagger$ As the summer advances they increase in size, and are actually the little fish which afford the angler in salmon rivers so much light amusement with the rod, during the months of August, September, and October. They remain over the

- On the approach of autumn, the whole of the Salmonidæ, resident as well as migratory, while in fresh water, acquire a dusky exterior, accompanied by a considerable increase of mucus or slime. The fins also become more muscular. However, on the return of spring, they resume their wonted beautiful colouring, and the fins, the cartilaginous portions of which are frequently damaged during the winter floods, grow up and acquire their former outline.

$\dagger$ " Pinks in the river Hodder, in the month of April, are rather more than three inches long, and VOL. XIV. PART II.

5 F 
second winter in the river, during which period the males shed their milt, and are found continuing their kind alongiwith the female adult salmon, although still bearing all the external markings of the parr, as I shall afterwards more particularly mention. No. 8 is a specimen eighteen months old, taken from pond No. 1, on the 14th November 1838. It measures 6 inches in length, and has now attained that stage when all the external characteristic markings of the parr are strikingly developed, and, in point of health and condition, cannot be exceeded by any taken from the river. All the males, at the age of eighteen months, of the several broods in my possession, last autumn (1838) attained a most important corroborative stage, viz. that of shewing a breeding state, by having matured the milt, which could be made to flow freely from their bodies, by the slightest pressure of the hand. The females of the same broods, however, although in equal health and condition, did not exhibit a corresponding appearance in regard to the maturing of roe. The male and female parrs in the river, of a similar age, are found respectively in precisely a corresponding state, which may surely be admitted as most important evidence in support of the fact, that all these individuals are, in truth, specifically the same.

No. 9 is a specimen two years old, taken from pond No. 1, on the 20th May 1839, after having assumed the migratory dress. The commencement of the change, which was perfected by the whole of the broods about the same time,* was first observable about the middle of the previous April, by the caudal, pectoral, and dorsal fins assuming a dusky margin, while, at the same time, the whole of the fish exhibited symptoms of a silvery exterior, as well as an increased elegance of form. The specimen in question, so recently a parr, exhibits a very perfect example of the salmon fry or smolt.

When the migratory change takes place in the young salmon in the ponds, a marked alteration also occurs in their habits. While in the parr state, they shew no disposition to congregate, but each individual occupies a particular station in the ponds, and should any one quit his place with the view of occupying the position already possessed by another, the intruder is at once expelled with an apparent degree of violence. But so soon as the whole brood has perfected the migratory dress, they immediately congregate into a shoal, and exhibit an anxious

are considered to be the fry of that year; at this time smolts of six inches and a half are also taken." See Yarrell's Supplement to British Fishes, page 6. The fry of the same year, in mild winters, are only quitting the gravel in April, at which stage they measure not more than one inch.-J. S.

* One or two of each of the three broods assumed the migratory or smolt dress at the age of twelve months. This circumstance I am disposed to attribute to the high temperature of the spring-water ponds, which I have no doubt has hastened the change. I am greatly strengthened in this opinion by the fact of no instance of a sinilar change having occurred with individuals reared in similar ponds supplied with water from a rivulet, the temperature of which throughout the year ranges pretty nearly with that of the River Nith. 
desire to effect their escape, by scouring all over the ponds, leaping and sporting, and altogether displaying a vastly increased degree of activity.

No. 10 is a specimen twenty months old, taken from pond No. 3, on the 5th January 1839. It measures 6 inches in length, and still displays all the characteristic markings of the parr.

No. 11 is a specimen two years old, also taken from pond No. 3, on the 24th May 1839. After assuming the migratory dress, it measures about $6 \frac{1}{2}$ inches in length, being about the average size of the brood. I have elsewhere stated that " the circumstances attending the development and growth of the brood in pond No. 3, so exactly correspond with those of the preceding brood in pond No. 1, that their history would only be a repetition of the former. I may, however, state, that the individuals in pond No. 3 are considerably larger than those in pond No. 1, the difference, at the age of six months, amounting to an inch."* This superiority in point of size, for the first six months, of those in pond No. 3, over those reared in pond No. 1, was not, however, maintained, with the exception of two individuals, much beyond the first six months, as by the period at which they assumed the migratory dress (two years), no difference existed in regard either to size or condition.

In order to be more distinctly understood regarding the specimen next in order (No. 12), the history of which is most interesting, and highly important in establishing the identity of the parr and salmon, it will be necessary here to recur to a passage in my former communication on this subject, where I stated that "pond No. 2, was occupied by a brood of young salmon also produced by artificial impregnation, the history of which should form the subject of another paper, after I had an opportunity of verifying the experiment by repetition." $\dagger$ I have now repeatedly verified the experiment alluded to, and take this opportunity of giving publicity to the very extraordinary nature of the results.

The circumstance of the male parrs with the milt matured, and flowing in profusion from their bodies, being at all times found in company with the adult female salmon while depositing her spawn in the river, and the female parrs being in every instance absent, suggested the idea that the males were probably present with the female salmon at such seasons for a sexual purpose. And to demonstrate the fact, $\mathrm{I}$, in January 1837, took a female salmon weighing $1.4 \mathrm{lb}$. from the spawning bed, from whence I also took a male parr weighing $1 \frac{1}{2} \mathrm{oz}$, with the milt of which I impregnated a quantity of her ova, and placed it in the stream E, pond No. 2 (See Plate XXI), where, to my great astonishment, the process succeeded in every respect as it had done with that which had been impregnated by the adult male salmon, and exhibited, from the first visible appearance of the embryo fish up to their assuming the migratory dress, the utmost health and vigour. The very ex-

* Edinburgh New Phil. Journ. for January 1838 (vol. xxiv. p. 172, note).

$\dagger$ lbid. same page. 
traordinary results of these experiments, although made with the utmost possible care, induced me to defer giving them publicity until I had repeatedly verified the fact. I, therefore, removed this brood to another pond, apart from all other fish, where they had an abundant supply of insect food and wholesome water ; and again, early in the following January (1838), I repeated the experiment by taking another female salmon, weighing $14 \mathrm{lb}$, and two male parrs from the same spawning bed (See parent specimens marked A), and impregnated two lots of her ova with the milt from the two parrs, and afterwards placed them in two different streams, inclosed in boxes open at the top, temperature $45^{\circ}$. The extreme severity of the weather which succeeded had, however, nearly proved fatal to the whole. On the evening of the 8th January, the day on which I took the parents from the river, the frost set in, and continued with such intensity for a succession of many weeks, that the wild fowl generally, and the wild ducks in particular, suffered severe privations, and in the course of their wanderings in search of food they unfortunately stumbled on my boxes of ova, one lot of which they wholly devoured, to the amount at least of 500. My feelings of mortification and disappointment on the discovery of this unforeseen disaster may readily be conceived. However, on examining my other box, I found there were still a few remaining, which I carefully collected, and put into a place of greater safety. The progressive growth of these, from the impregnation of the ova up to the age of eighteen months (See specimens A), has also been uniformly the same as those produced by male and female adult parents, and reared under similar circumstances.

As a further illustration of the singular economy of the salmon in their native streams, I have yet to detail another experiment or two, not less interesting than conclusive. In December last (1838) I took a female salmon from the river weighing $11 \mathrm{lb}$., and four male parrs from the same spawning bed. After impregnating four different lots of her ova, one lot to each individual parr, I placed the four parrs in a pond, where they remained until the following May, at which period they assumed the migratory dress. (See specimen No. 13.) The ova were placed in streams to which no other fish had access, and where they became mature in a similarly progressive manner to those already detailed, thus clearly demonstrating that the young salmon of eighteen months old, while yet in the parr or early state, actually perform the duties of a male parent before quitting the river.*

* As I believe it has been objected to my views, or rather practice, regarding this mode of impregnation, that the generative influence may have been in some other way effected than through the medium of the parr, I therefore took every means to prove the truthful results of my experiments by varying in some measure their conditions. Thus, in two instances, I took a portion of the ova from a female salmon, and placed them, without impregnation, in a stream of pure water. The result was as I anticipated :- up to the termination of the general hatching season they exhibited no appearance of vitality. The female from which one lot of ova was taken, and placed in water without impregnation, was the 
While the males of the three several broods which occupy ponds No. 1, 2 , and 3 , continued in a breeding state, which lasted throughout the whole of the winter of 1838-39, I impregnated the ova of three adult female salmon from the river with the milt of a male taken from each of the three ponds, the whole of which ova matured. This at once removes any doubt which may have been entertained regarding the constitutional strength of individuals reared under such circumstances.

Specimen No. 12, is one of the males used in the above experiments, and is itself the produce between a male parr and female adult salmon taken from the river on the 4th January 1837, and reared in pond No. 2, as already mentioned. The result of the experiment practised with this specimen and the female salmon from the river, being of the utmost importance in establishing the identity of the species (on a principle recognised by physiologists as a law of nature), every necessary precaution to avoid error or confusion was observed. It was taken from pond No. 2 on the 5th January 1839, being then twenty months old, with the milt flowing from its body. A female adult salmon weighing twelve lb. (see parent specimen, B.) was taken at the same time from the river, in the act of spawning in the absence of the male. A quantity of her ova was impregnated in the same manner in every respect as practised in the preceding experiments, and, for the better security of the lot, the whole was placed in a wooden trough, over which a sheet of fine copper-wire gauze was fixed. The trough was then placed in a stream of water previously prepared for its reception, and the results were precisely of a corresponding nature to those already detailed, the embryo fish becoming visible after fifty-five days, and being excluded from the egg at the end of 109 days after impregnation, under a temperature of $40^{\circ}$.

It has been maintained by individuals whose opinions are opposed to mine on this question, that the parr is a distinct species, and that, by a forced connection between it and the female salmon, I was producing a hybrid. This idea at once brings the importance of the last experiment more immediately into view, from the circumstance of the male parent of specimen No. 12 being actually a parr, while No. 12 itself, the alleged hybrid, in its turn became the parent of a numerous brood. (See specimens, B.)

Were these two species, then, really distinct, it would follow that the produce would be hybrids, and " nature herself has provided against the confusion of different species by a conservative law, according to which all hybrids are

female with which the four parrs above alluded to were spawned. They were placed in the same stream but in a separate vessel from the four lots impregnated. The other lot was taken from the female with which the male from pond No. 3. was spawned. The unimpregnated lot was placed in the same stream with the former. The impregnated lot was placed in the stream of pond No. 3. To avoid contact the unimpregnated lots were in each case taken first, and removed to a distance. 
barren :" consequently, upon this principle-a law in the economy of naturethe parr and salmon are really identical in species, as proved by the fact now narrated, of the young produced between them having actually the power of reproducing their kind.

Apart from these experiments, it was at one time held, that the parrs found in their native streams were hybrids, from the anomalous circumstance of the males being always found in the autumn with the milt matured, while females, of a corresponding size, could at no season be found exhibiting the least approximation to a breeding state.* However, this idea, if it ever was seriously entertained by scientific men, has now given way to the opinion " that they are a distinct species, and have no connection whatever with the migratory salmon." $\dagger$ Were the parr a distinct species, the result of their attendance on the female salmon would have the effect of producing universal confusion among the migratory inhabitants of rivers, from the circumstance of the male parrs in a breeding state occupying in great numbers the very centre of the salmon spawning bed, while the female salmon herself is at the same instant pouring thousands of her ova into the very spot where they are thus genially congregated.

Had these extraordinary results proceeded from a solitary experiment, there might have been some ground for believing that I was probably deceiving myself, and, consequently, misleading others, - a fear I myself at first entertained. But after such a series of experiments, made with all possible care, and uniformly ending in the same results, the fact can no longer, I conceive, admit of doubt. Having altogether within these last two years, made eight distinct experiments by artificially impregnating the ova of the salmon with the milt of a corresponding number of male parrs from the river, besides three experiments with those of eighteen-month-old parrs from the pond-each with perfect success-I trust that I have thrown some interesting light on the breeding of parrs, - a subject which has hitherto defeated all inquiry when sought after on the principle of their breeding among themselves as a distinct species.

* Solitary instances have occurred of large female parrs having been found in salmon rivers with the roe considerably developed, and I find, by detaining the female smolts in fresh water until the end of the third winter, that individuals are found in this comparatively mature condition. From this fact, therefore, it may be inferred, that the large parr, either male or female, of nine and ten inches in length, which are occasionally found in rivers, are the young of the salmon, which, for some natural reason, had not been prepared to migrate at the ordinary period, and had, therefore, remained for another year in the fresh water.

† Recent experiments having been made on the young of the salmon by very competent individuals, it is now admitted that they " remain one year in the river before they go to the sea as smolts." However, owing to these fishes having escaped the observation of those individuals during the intermediate stage, that is, from the ovum up to the length of three inches, they were actually twelve months old at the commencement of the experiments referred to by Mr Yarrell, in place of being the "fry of that year."-See Mr Yarrell's Supplement to British Fishes. 
The fact of the young salmon propagating its kind while it is yet itself in other respects in an immature condition, is certainly an extraordinary departure from the ordinary laws of nature, so far, at least, as land animals are concerned. From certain observed facts, however, there is reason to believe that the economy of the class of fishes differs in this respect from that of land animals-a disparity which, in consequence of the medium they inhabit, has hitherto escaped the observation of the naturalist. As the young of the other migratory species do not quit the river during the first year, it is probable that they also observe a similar economy to that of their more valuable congener.

It has been generally supposed that the male salmon, during the spawning season, assists the female in forming the spawning bed. This idea is, I think, founded in error, as, during the whole course of my experience, I have never been able to detect the male taking any share whatever in the more laborious portion of these parental duties. The only part he performs, beyond the mere sexual function, consists in the unwearied vigilance which he exhibits in protecting the spawning-bed from the intrusion of rival males, all of which he assiduously endeavours to expel. The female, regardless of the occasional absence of the males during these contests, and probably satisfied with the presence of the male parrs, proceeds with her operations by throwing herself at intervals of a few minutes upon her side, and while in that position, by the rapid action of her tail,* she digs a receptacle in the gravel for her ova, a portion of which she deposits, and, again turning upon her side, she covers it up by a renewed action of the tail,ternately digging, depositing, and covering ova, until the process is completed by the laying of the whole mass, an operation which generally occupies three or four days. In the course of these experiments, it has been ascertained that the milt of a single male parr, whose entire weight may not exceed one and a-half ounce, is capable, when confined in a small stream, of effectually impregnating all the ova of a very large female salmon. On the spawn first quitting the body of the female, it is found to be enveloped in a thin coating of viscous matter, which the action of the water does not immediately destroy, but which continues to admit of a partial adherence to the gravel at the bottom of the spawning-bed, where the ova receive the necessary fecundation of the milt, and are afterwards covered with gravel by the instinctive efforts of the female parent, in the manner above described.

How long these ova will remain excluded from the body of the female, and yet continue capable of receiving with effect the fecundating action of the milt, I have not hitherto ascertained. I have, however, made several experiments on

* I am aware it has been a matter of dispute amongst observers as to which of the two extremities of the fish is employed in the formation of the spawning-bed. However, from late opportunities of observation, which rarely occur, owing to the turbid state of the river in the spawning season, I am now satisfied that it is by the action of the caudal extremity alone that the gravel is removed. 
the ova after the parent had been a considerable time dead, and removed from the river. In one particular instance, the female had been dead for nearly two hours without the vital principle of the spawn being in the least degree affected,-as, on being afterwards placed in water, and the milt of a living male poured upon it, it exhibited within the usual period the same healthy and progressing vivification, under a similar temperature, as that taken and impregnated the moment it quitted the body of the living parent. I have merely stated this fact as being in part corroborative, so far as relates to the salmon, of similar experiments made by M. JACOBI on individuals of the same genus.

The extraordinary nature of the experiments made with the parr and salmon, I have no doubt will tend to stagger the belief of many who may be disposed to admit the truth of the facts resulting from the experiments upon the adult fishes. Nevertheless, they are strictly true; and I would strongly recommend that all those interested should immediately turn their attention to a subject so curious in a zoological point of view, and so important in its bearings on the history of the most highly prized of all the species which ever sojourn in our river waters.

\section{ILLUSTRATIVE PLATES.}

Plate XXI. exhibits a plan of the Experimental Ponds, as constructed by Mr Shaw, and described at p. 553 .

Plate XXII. contains representations of Parr or Salmon-Fry, in various stages from the ovum to the age of two years,--by which period the characteristic aspect of the Smolt (commonly so called) has been assumed. This Plate is lettered in such a manner as to explain itself, and therefore need not here be more particularly described. 
TO ILLUSTRATE MR SHAW'S EXPERIMENTS ON THE OVA OF THE SALMON.

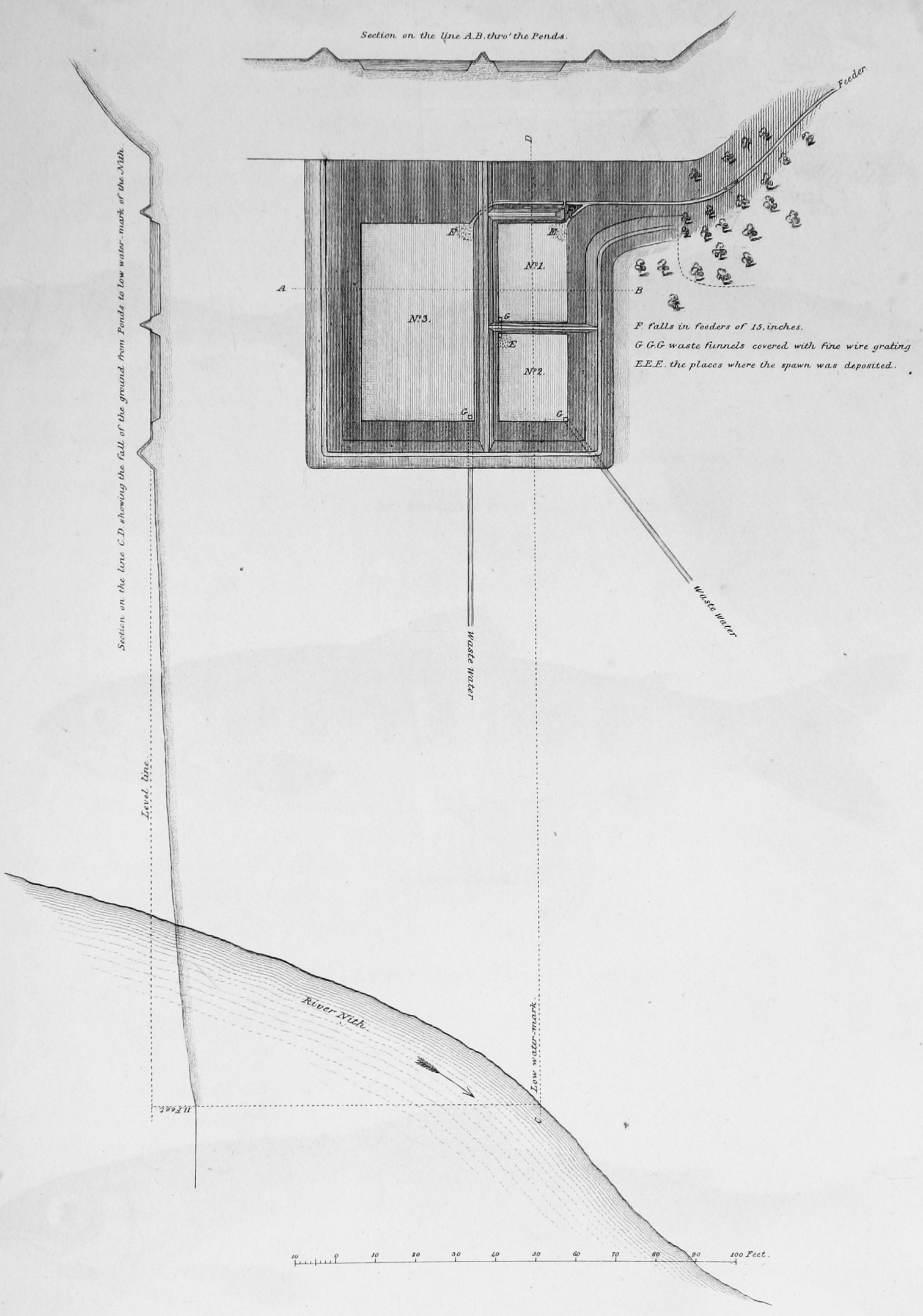




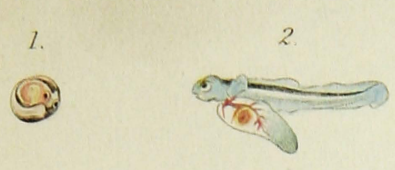

Day before hatching.
One day old.

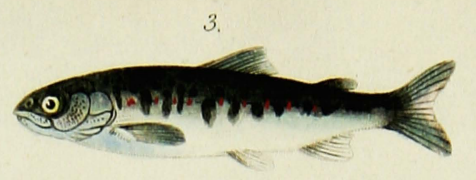

Two months old.

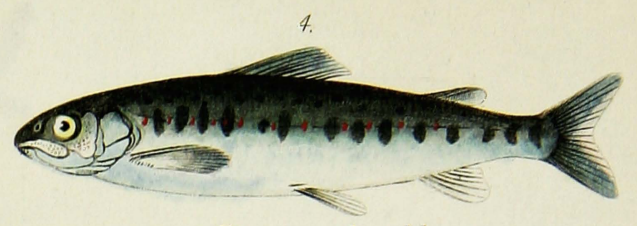

Four months old.

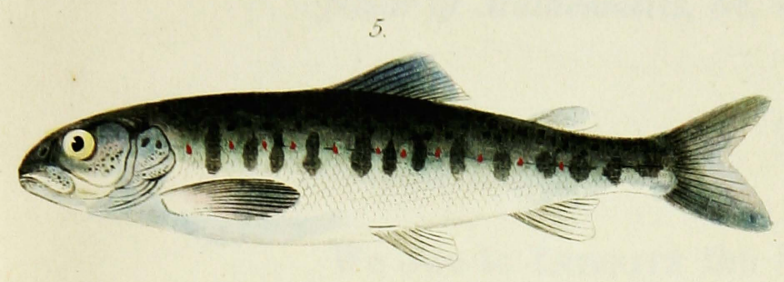

Six months old.

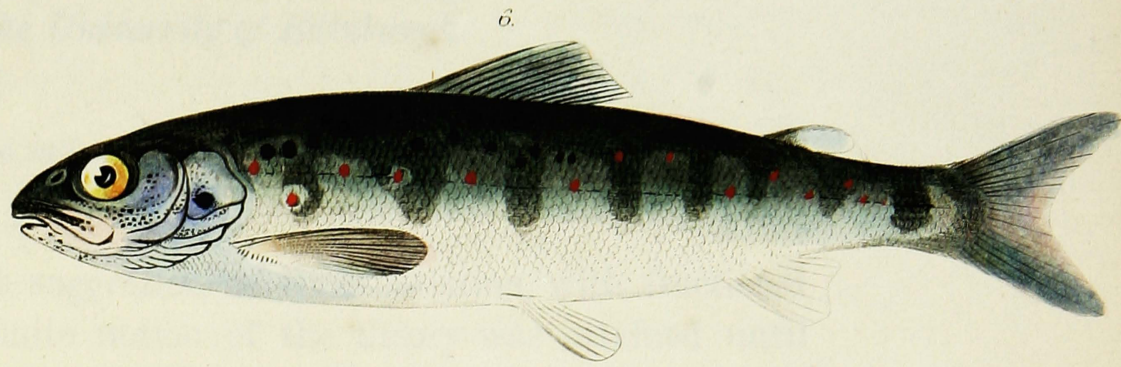

Twelve months old

The above are Parr produced from the ova of Salmon

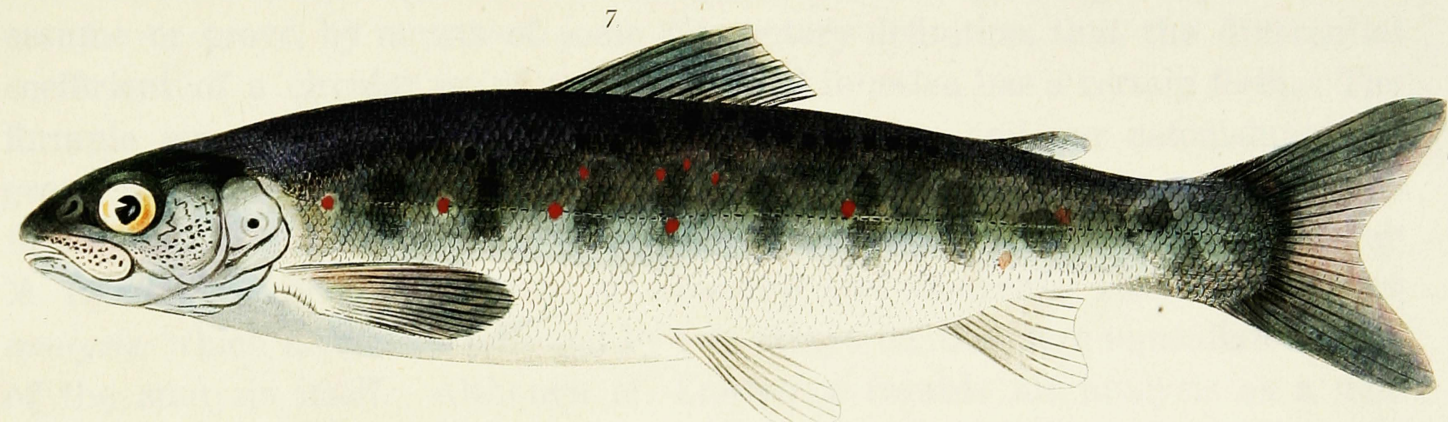

Eighteen months old

$N_{\text {". }} 7 \& 8$, bore the same aspect at the same age.

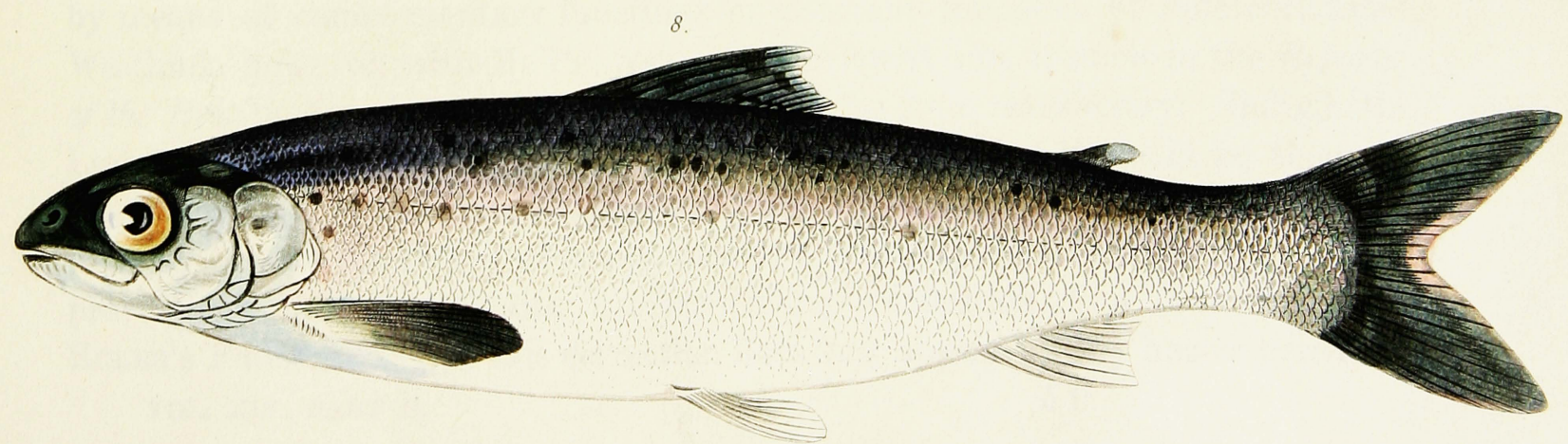

